\title{
EDITORIAL
}

\section{Serotonin transporter gene polymorphisms in irritable bowel syndrome}

\author{
B. GEERAERTS, L. VAN OUDENHOVE \& J. TACK
}

Department of Internal Medicine, Gastroenterology Section, Faculty of Medicine, University of Leuven, Leuven, Belgium

Irritable bowel syndrome (IBS) is a symptomatic motility and sensory disorder of the lower gastrointestinal (GI) tract and is characterized by abdominal pain/ discomfort, bloating and altered bowel activity. It is usually classified according to the predominant bowel habit - IBS with constipation (C-IBS), IBS with diarrhoea (D-IBS) or IBS with alternating symptoms of both constipation and diarrhoea. ${ }^{1}$ Despite intensive research, the complicated and multifactorial pathophysiology underlying IBS is not completely understood. Recently, there is growing emphasis on identifying specific biological pathways that contribute to the complex pathophysiology of this disease.

\section{SERT AND SERT POLYMORPHISMS}

Serotonin [5-hydroxytryptamine (5-HT)], which is released from enterochromaffin cells and enteric neurons, is a key neurotransmitter modulating various GI functions, including secretion, motility and visceral perception (reviewed by Gershon, ${ }^{2}$ ). To prevent excessive 5-HT signalling and 5-HT receptor desensitization, the actions of enteric 5-HT are terminated by reuptake through the serotonin transporter protein (SERT). ${ }^{3}$

The relevance of serotonin reuptake for the control of GI functions was confirmed by reports of disturbed GI motility in SERT knockout mice ${ }^{4}$ and by alterations in colonic sensorimotor function after acute inhibition

Address for correspondence

Professor Dr Jan Tack, Department of Internal Medicine, Gastroenterology Section - Center for Gastroenterological

Research, University Hospital Gasthuisberg - University of Leuven, Herestraat, 49, B-3000 Leuven, Belgium.

Tel: +32 16 345751; fax: +32 16 345939;

e-mail: jan.tack@med.kuleuven.be

Received: 17 August 2006

Accepted for publication: 17 August 2006 of SERT function in man. ${ }^{5}$ These observations provide a basis for potential involvement of genetic variations in SERT in motility related disorders such as IBS. Human SERT is encoded by a single gene on chromosome $17 \mathrm{q} 11$ and the approved gene symbol for SERT is SLC6A4 (solute carrier family 6 member 4). Two polymorphic sites in the SERT gene have attracted interest: variable number of tandem repeats (VNTR) in the gene's second intron, ${ }^{6}$ first described by Heils et al., ${ }^{7}$ and the SERT gene linked polymorphic region (SERT-P, originally known as 5-HTTLPR). The latter consists of a 44 base pair deletion or insertion in the $5^{\prime}$ flanking promoter region, resulting in a short (s) and a long (1) allele respectively.

The functional impact of VNTR is not well known, but the SERT-P polymorphism seems to be functionally relevant as it modulates SERT gene transcription and, consequently, 5-HT reuptake and availability. One study showed that compared with the homozygous long (1/1) genotype, polymorphic heterozygous (1/ s) and homozygous short (s/s) SERT-P were associated with reduced function of the transporter protein in a lymphoblastoid cell line. ${ }^{8}$ Consistent with the effects of serotonin in the gut, SERT-P polymorphisms could potentially be involved in the development of IBS. This has mainly lead to the hypothesis that the $\mathrm{s} / \mathrm{s}$ and $1 / \mathrm{s}$ SERT-P genotypes are associated with prolonged serotonergic activity, which may lead to diarrhoea.

\section{SERT POLYMORPHISMS IN IBS}

To investigate this hypothesis, several studies have tried to assess a relationship between IBS and SERT polymorphisms. A Turkish study by Pata et al. ${ }^{9}$ reported an association of D-IBS with the 1/s SERT-P genotype. In addition, the authors also described an 


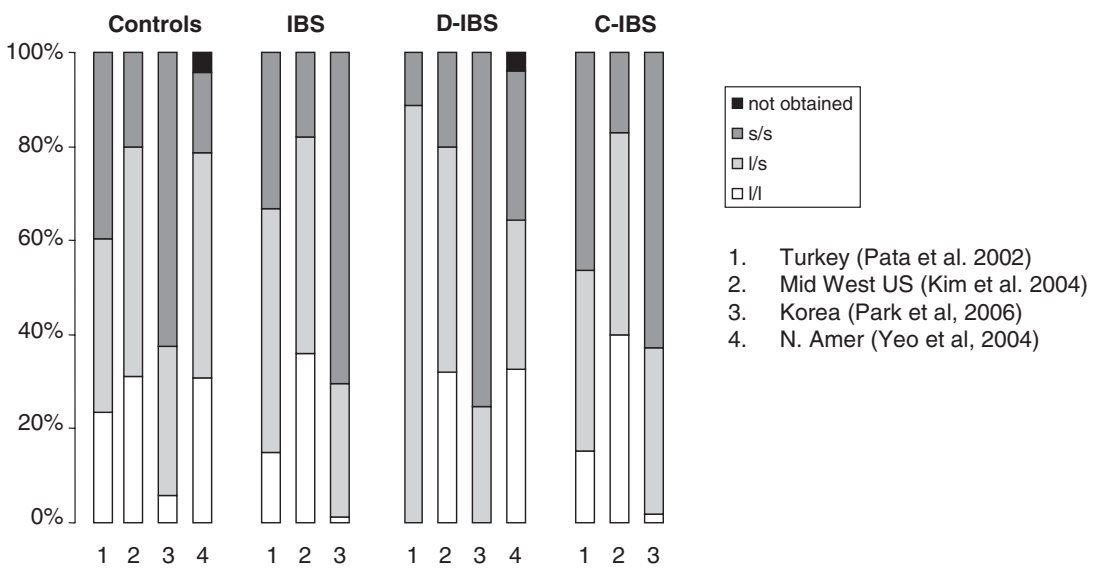

\begin{abstract}
Figure 1 Proportion of different serotonin transporter protein linked polymorphic region (SERT-P) genotypes in different irritable bowel syndrome (IBS) phenotypes (IBS overall, diarrhoea predominant IBS and constipation predominant IBS). Note the heterogeneous distribution of SERT-P polymorphisms in different ethnic study samples. The represented studies were performed in Turkey (Pata et al.), the US (Kim et al., Yeo et al.) and Korea (Park et al.).
\end{abstract}

unexpected and remarkable association between the s/ $s$ genotype and C-IBS. A study in a cohort of US patients recruited for alosetron clinical trials by Yeo et al. ${ }^{10}$ reported a significant association between the homozygous short SERT-P genotype and D-IBS in females. In another US study by Kim et al., ${ }^{11}$ the distribution of SERT polymorphisms was not significantly different between patients with lower functional gastrointestinal disorders (FGID) vs controls, and between the subset with the D-IBS phenotype vs controls. The most recent study, performed in Korea by Park et al. published in the current issue of Neurogastroenterology and Motility, ${ }^{12}$ again found an association between the s/s SERT-P genotype and D-IBS. The results from these four recent genetic association studies are summarized in Fig. 1 and clearly indicate the heterogeneous distribution of these polymorphisms in different study samples. Contrasting observations in these population-based association studies may be explained by differences of prevalence of SERT-P genotypes in the background population and by differences in patient selection. However, they mainly indicated that the role for SERT-P polymorphisms in the pathogenesis of IBS will at best be modest.

\section{SERT POLYMORPHISMS AND DRUG RESPONSIVENESS}

Altered serotonergic availability in the gut as consequence of SERT-P polymorphisms might interfere with the effectiveness of serotonergic agents and can result in altered response to medication. A pharmacogenetic study by Camilleri et al. ${ }^{13}$ investigated the change in colonic transit after administration of alosetron, a $5-\mathrm{HT}_{3}$ receptor antagonist, in D-IBS patients with different SERT-P genotypes. The authors reported an association of the homozygous long polymorphism of the SERT-P with greater response to alosetron, but the sample size was limited, and more data are needed to confirm these findings.

\section{SERT POLYMORPHISMS AND PSYCHIATRIC DISORDERS}

The effects of SERT dysfunction are not restricted to the gut. Enteric SERT is similar to that in the brain within the same species. ${ }^{14}$ It is generally known that IBS patients frequently suffer from comorbid psychiatric disorders. Neural circuits involved in emotion regulation are densely innervated by $5-\mathrm{HT}$ neurons originating in the raphe nuclei. These networks are implicated in the pathophysiology of mood and anxiety disorders. Thus, differences in SERT expression and function as a consequence of gene polymorphisms may critically influence psycho(patho)logical processes. Several studies independently reported increased anxiety-like behaviour in SERT knockout mice, ${ }_{1}^{15,16}$ which is indicative for a link between SERT expression and anxiety. In humans, decreased SERT gene function has been related to anxiety, stress reactivity and depression (reviewed by Hariri and Holmes, ${ }^{17}$ ). The implication of SERT polymorphisms in anxiety regulation may be relevant to IBS, as evidence for a reciprocal interaction between anxiety and GI sensorimotor function through the brain-gut axis is growing. ${ }^{18,19}$

In conclusion, the best approach to study a multidimensional disorder as IBS is to try to unravel the pathophysiology at all levels, including the genetic level, and the complex interaction between those different levels (e.g. gene-environment interactions). Genes can impact human physiology at all levels and therefore provide a meaningful target for future research. In the case of functional bowel disorders, 
however, the pathogenesis is likely to be multifactorial, with single gene mutations representing only one of several factors.

\section{REFERENCES}

1 Guilera M, Balboa A, Mearin F. Bowel habit subtypes and temporal patterns in irritable bowel syndrome: systematic review. Am J Gastroenterol 2005; 100: 1174-84.

2 Gershon MD. Review article: roles played by 5-hydroxytryptamine in the physiology of the bowel. Aliment Pharmacol Ther 1999; 13 (Suppl. 2): 15-30.

3 Fuller RW, Wong DT. Serotonin uptake and serotonin uptake inhibition. Ann N Y Acad Sci 1990; 600: 68-78 (discussion 79-80).

4 Chen JJ, Li Z, Pan H et al. Maintenance of serotonin in the intestinal mucosa and ganglia of mice that lack the highaffinity serotonin transporter: abnormal intestinal motility and the expression of cation transporters. I Neurosci 2001; 21: 6348-61.

5 Tack J, Broekaert D, Corsetti M, Fischler B, Janssens J. Influence of acute serotonin reuptake inhibition on colonic sensorimotor function in man. Aliment Pharmacol Ther 2006; 23: 265-74.

6 Lesch KP, Balling U, Gross J et al. Organization of the human serotonin transporter gene. I Neural Transm Gen Sect 1994; 95: 157-62.

7 Heils A, Teufel A, Petri S et al. Allelic variation of human serotonin transporter gene expression. J Neurochem 1996; 66: 2621-4.

8 Lesch KP, Bengel D, Heils A et al. Association of anxietyrelated traits with a polymorphism in the serotonin transporter gene regulatory region. Science 1996; 274: 1527-31.

9 Pata C, Erdal ME, Derici E, Yazar A, Kanik A, Ulu O. Serotonin transporter gene polymorphism in irritable bowel syndrome. Am J Gastroenterol 2002; 97: 1780-4.
10 Yeo A, Boyd P, Lumsden S et al. Association between a functional polymorphism in the serotonin transporter gene and diarrhoea predominant irritable bowel syndrome in women. Gut 2004; 53: 1452-8.

11 Kim HJ, Camilleri M, Carlson PJ et al. Association of distinct alpha(2) adrenoceptor and serotonin transporter polymorphisms with constipation and somatic symptoms in functional gastrointestinal disorders. Gut 2004; 53: 82937.

12 Park JM, Choi MG, Park JA et al. Serotonin transporter gene polymorphism and irritable bowel syndrome. Neurogastroenterol Motil 2006; 18: 995-1000.

13 Camilleri M, Atanasova E, Carlson PJ et al. Serotonintransporter polymorphism pharmacogenetics in diarrheapredominant irritable bowel syndrome. Gastroenterology 2002; 123: 425-32.

14 Masson J, Sagne C, Hamon M, El Mestikawy S. Neurotransmitter transporters in the central nervous system. Pharmacol Rev 1999; 51: 439-64.

15 Holmes A, Lit Q, Murphy D et al. Abnormal anxietyrelated behavior in serotonin transporter null mutant mice: the influence of genetic background. Genes Brain Behav 2003; 2: 365-80.

16 Ansorge MS, Zhou M, Lira A, Hen R, Gingrich JA. Earlylife blockade of the 5-HT transporter alters emotional behavior in adult mice. Science 2004; 306: 879-81.

17 Hariri AR, Holmes A. Genetics of emotional regulation: the role of the serotonin transporter in neural function. Trends Cogn Sci 2006; 10: 182-91.

18 Mayer EA, Craske M, Naliboff BD. Depression, anxiety, and the gastrointestinal system. J Clin Psychiatry 2001; 62 (Suppl. 8): 28-36 (discussion 37).

19 Van Oudenhove L, Demyttenaere K, Tack J, Aziz Q. Central nervous system involvement in functional gastrointestinal disorders. Best Pract Res Clin Gastroenterol 2004; 18: 663-80. 